\title{
ANALISIS SEMIOTIKA ROLAND BARTHES PADA IKLAN SUSU SGM EKSPLOR VERSI "TUNJUK TANGAN"
}

\author{
Nurul Ihza'), Dafa Raudhatul Jannah ${ }^{2)}$ \\ Program Studi Desain Komunikasi Visual \\ Fakultas Bahasa dan Seni, Universitas Indraprasta PGRI \\ Jl. Nangka No. 58 C, Tanjung Barat, Jakarta Selatan, 12530, Indonesia \\ dafaraudhatul@gmail.com
}

\begin{abstract}
Abstrak
Susu SGM ialah salah satu merek susu di Indonesia yang memiliki varian sesuai dengan kebutuhan ibu hamil dan menyusui hingga anak-anak. Susu SGM juga mempertimbangkan dan mengelola produk susu formulanya sebaik mungkin agar generasi di Indonesia lebih maju. Pada salah satu iklan susu SGM, mereka memberikan sentuhan yang berbeda dengan iklan susu pada umumnya. Mengiklankan produk dan dibalut dengan keberagaman Indonesia adalah salah satu iklan susu SGM yang sangat memikat perhatian masyarakat agar membuka matanya untuk melihat betapa indahnya Indonesia apabila generasi Indonesia dapat lebih maju dengan cara memenuhi kebutuhan nutrisi. Dengan adanya iklan tersebut, kami tertarik untuk membahasnya pada artikel ini. Metode yang kami gunakan pada penelitian ini ialah kualitatif. Teori yang kami gunakan pada penelitian ini ialah teori Barthes. Teori ini terdiri dari tiga hal ialah denotasi, konotasi dan mitos. Akan tetapi, kami hanya menggunakan dua hal yaitu denotasi dan konotasi.
\end{abstract}

Kata Kunci: Susu SGM, anak-anak, Iklan, Budaya Indonesia, Kualitatif, Teori Barthes.

\begin{abstract}
SGM milk is one of many kinds milk branding in Indonesia which is has various type of milk according to the need from pregnant milk, breast feeding milk to child milk. SGM milk also manages and considers its formula milk as best as possible to support Indonesian generation to become more advance. In one of SGM milk's advertisement, they had a different touch of milk advertisement than others. They sell their milk combined with the diversity of Indonesia that made this advertisement catch more public attentions and open public eyes that how beautiful Indonesia if nutrition takes a big part to make Indonesian generation became more advance. That advertisement interests us to be discussed in this article. We choose qualitative method to be used to this research. We also use Roland Barthes theory to this research. This theory has 3 points is denotation, connotation, and myth. But we just use 2 points is denotation and connotation.
\end{abstract}

Keywords: SGM milk, children, advertisement, culture of Indonesia, qualitative, the theory of Roland Barthes.

Correspondence author: Dafa Raudhatul Jannah, dafaraudhatul@ gmail.com, Jakarta, and Indonesia 


\section{PENDAHULUAN}

Indonesia merupakan negara yang memiliki beragam suku, bangsa, bahasa, dan budaya. Banyak sekali pelajaran yang dapat diambil dari keberagaman budaya Indonesia. Banyak media informasi yang membahas hingga menggunakan keberagaman Indonesia dengan tujuan yang baik, dikemas dengan karya yang menarik, dan pesan yang disampaikan mudah untuk dicerna. Media informasi itu sendiri merupakan suatu alat atau sarana untuk memperkenalkan dan menawarkan suatu produk atau jasa dan lain semacamnya agar dapat dengan mudah diketahui oleh masyarakat luas.

Media promosi yang mudah kita temui ialah iklan. Iklan merupakan pesan yang menawarkan suatu produk yang ditunjukkan kepada masyarakat lewat suatu media (Kasali, 2017). Bukan hanya produk, tetapi banyak sekali macamnya yang dapat diiklankan. Salah satunya ialah iklan produk susu anak SGM.

Susu SGM merupakan salah satu dari produk yang dikelola dari PT Sarihusada Generasi Mahardika (Sarihusada). PT Sarihusada pun dapat dikatakan sudah berpengalaman dalam memproduksi produk nutrisi untuk ibu hamil dan menyusui dan anak sejak tahun 1954. Produk susu SGM ini ialah produk susu untuk ibu hamil dan menyusui dan anak-anak yang memiliki banyak variasi sesuai kebutuhan. Susu SGM juga memiliki website resmi yang membantu calon konsumen dalam memilih produk sesuai kebutuhan. Selain itu, di-website-nya juga terdapat banyak informasi mengenai ibu hamil dan menyusui, anak-anak, hingga promo yang diberikan oleh pihak susu SGM untuk para konsumen. Variasi yang didapat ialah dari produk susu SGM anak, yang diformulasikan sesuai dengan umur dan manfaat yang berbeda.

Susu SGM memiliki banyak iklan dan memiliki ciri khas tersendiri dalam iklannya. Pada setiap iklan susu SGM, model untuk setiap generasi akan mengacungkan jari telunjuk yang menggambarkan bahwa setiap anak yang mengkonsumsi produk susu SGM merupakan generasi maju dan cerdas. Susu SGM sangat memperhatikan kualitas produknya, salah satunya mengelompokkan nutrisi sesuai dengan kebutuhan umur. Dari banyaknya iklan susu SGM yang sudah banyak beredar, penulis memilih iklan dengan versi keberagaman Indonesia untuk dibahas. Iklan tersebut membuktikan bahwa susu SGM berusaha sekali untuk menyampaikan bahwa mereka memang sangat ingin membantu kebutuhan nutrisi di seluruh Indonesia. Penulis akan membahas makna dari iklan tersebut dengan teori semiotika Roland Barthes terhadap iklan susu SGM Eksplor versi "Tunjuk Tangan” yang menyuguhkan keberagaman Indonesia.

\section{METODE PENELITIAN}

Pengumpulan data pada dalam penelitian analisis teori semiotika (Roland Barthes) terhadap iklan susu SGM Eksplor versi "Tunjuk Tangan" dilakukan dengan metode penelitian kualitatif. Data kualitatif bertujuan untuk mengembangkan konsep pandangan pada masalah yang dihadapi, menerangkan fakta yang berkaitan dengan penelusuran teori. Data kualitatif yang kami gunakan adalah menggunakan Teknik observasi data. Terdapat dua jenis teori pengumpulan data, yakni data primer dan data sekunder. Namun, data yang kami kumpulkan bersifat sekunder. Pengumpulan data sekunder didapatkan dari buku maupun internet.

\section{HASIL DAN PEMBAHASAN}

\section{Iklan Susu SGM Versi “Tunjuk Tangan”}

Iklan atau Advertising merupakan salah satu jenis komunikasi yaitu komunikasi pemasaran, yang mana mengacu pada semua bentuk teknik komunikasi yang digunakan penjual/pedagang/pemasar untuk menjangkau calon konsumennya atau audience dan menyampaikan pesannya.

Iklan susu SGM Versi "Tunjuk Tangan" ini menarik untuk dibahas, karena berbeda dengan iklan susu formula lainnya. Di dalam iklan ini tidak hanya menggambarkan unsur keluarga antara ibu dan anak saja, namun terdapat unsur lain yaitu ketika anak-anak tumbuh menjadi dewasa yang pintar, sehat dan sukses dalam berkarier baik perempuan dan juga laki-laki. 
Iklan ini menunjukkan bahwa antara perempuan dan laki-laki memiliki kesetaraan. Selain itu, iklan ini juga ingin menunjukkan bahwa susu SGM dapat membuat anak tumbuh pintar, sehat, inspiratif dan sukses dengan tagline "Kalau kau anak SGM tunjuk tangan".
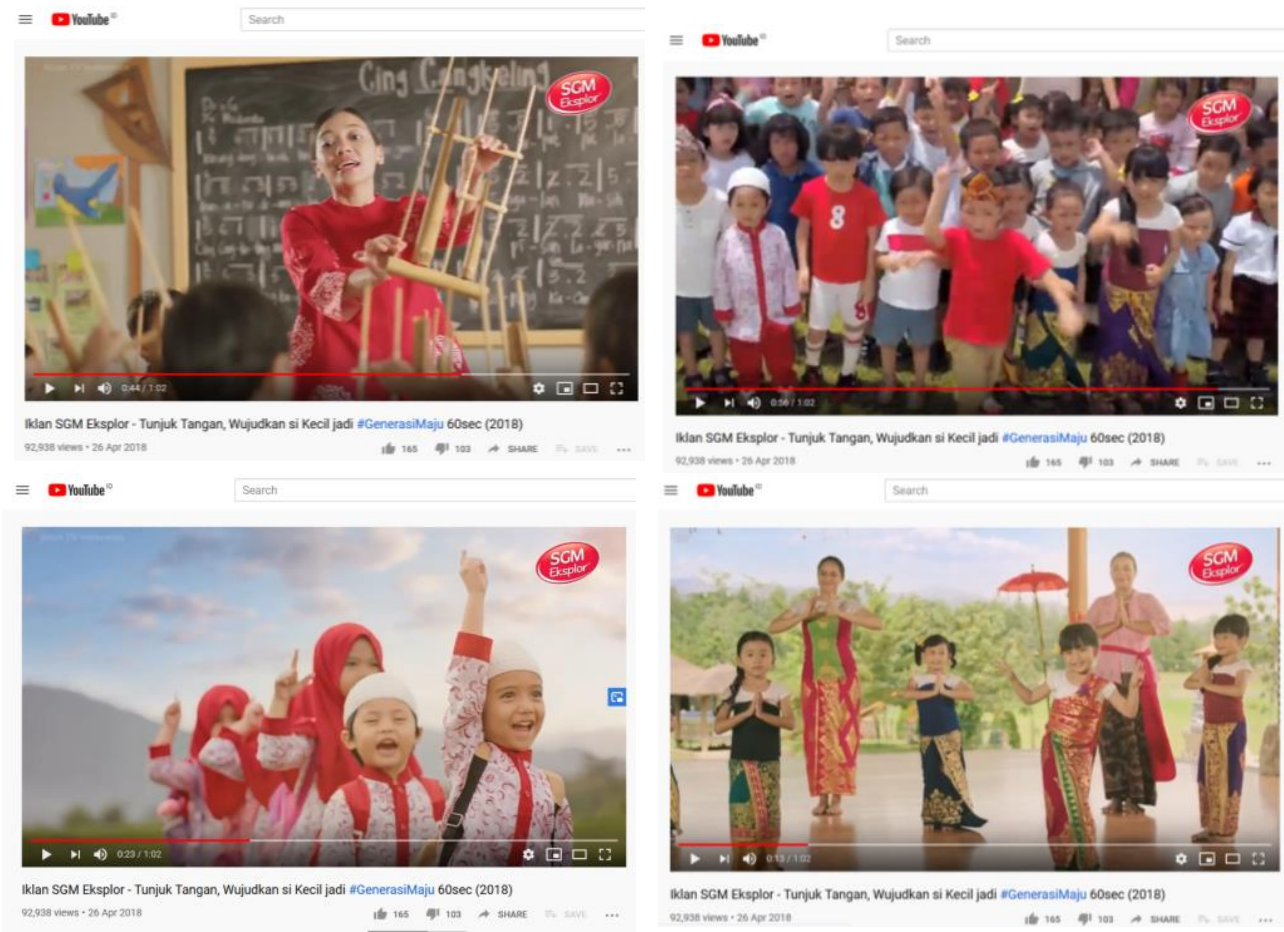

Gambar 1. Tangkapan Layan Iklan Susu SGM

Sumber: https://www.youtube.com/watch?v=KkFL-Fm9X90

Hal lain yang menarik dari iklan ini ialah adanya penggambaran tentang keberagaman budaya, sosial dan agama, juga kesetaraan sosial seperti yang digambarkan pada scene-scene di bawah ini.

\section{Analisis Semiotika Barthes pada Iklan Susu SGM Versi "Unjuk Tangan"}

Menurut Roland Barthes, semiotika adalah pembacaan tanda menunjuk pada gagasan tentang dua tatanan pertandaan (order of significations), yaitu denotasi dan konotasi. Denotasi atau denotatif menunjukkan pada data atau informasi yang tersurat pada gambar tersebut. Sedangkan konotasi atau konotatif adalah menunjuk pada hal-hal yang tersirat yang muncul pada pikiran pengamat sesaat sesudah melihat sebuah gambar. Selain itu Roland Barthes juga mengemukakan dalam metodenya yaitu adanya konsep dasar mitos. Mitos merupakan metode untuk membongkar kebudayaan manusia yang negatif. Semiotika bukan hanya meneliti tentang penanda dan petanda, tetapi juga hubungan mengikat mereka secara keseluruhan. Ia juga mengaplikasikan semiologi ini hampir dalam setiap segi kehidupan, seperti iklan, busana, film, sastra dan hal lainnya yang ada dalam peradaban manusia (Sobur, 2004: 68).

Analisis Semiotika Barthes memiliki tiga makna, yaitu denotasi, konotasi dan mitos, namun pada iklan susu SGM versi "tunjuk tangan" ini analisis yang peneliti lakukan hanya menggunakan makna denotasi dan konotasi saja. Berikut adalah hasil analisis semiotika dari iklan tersebut. 


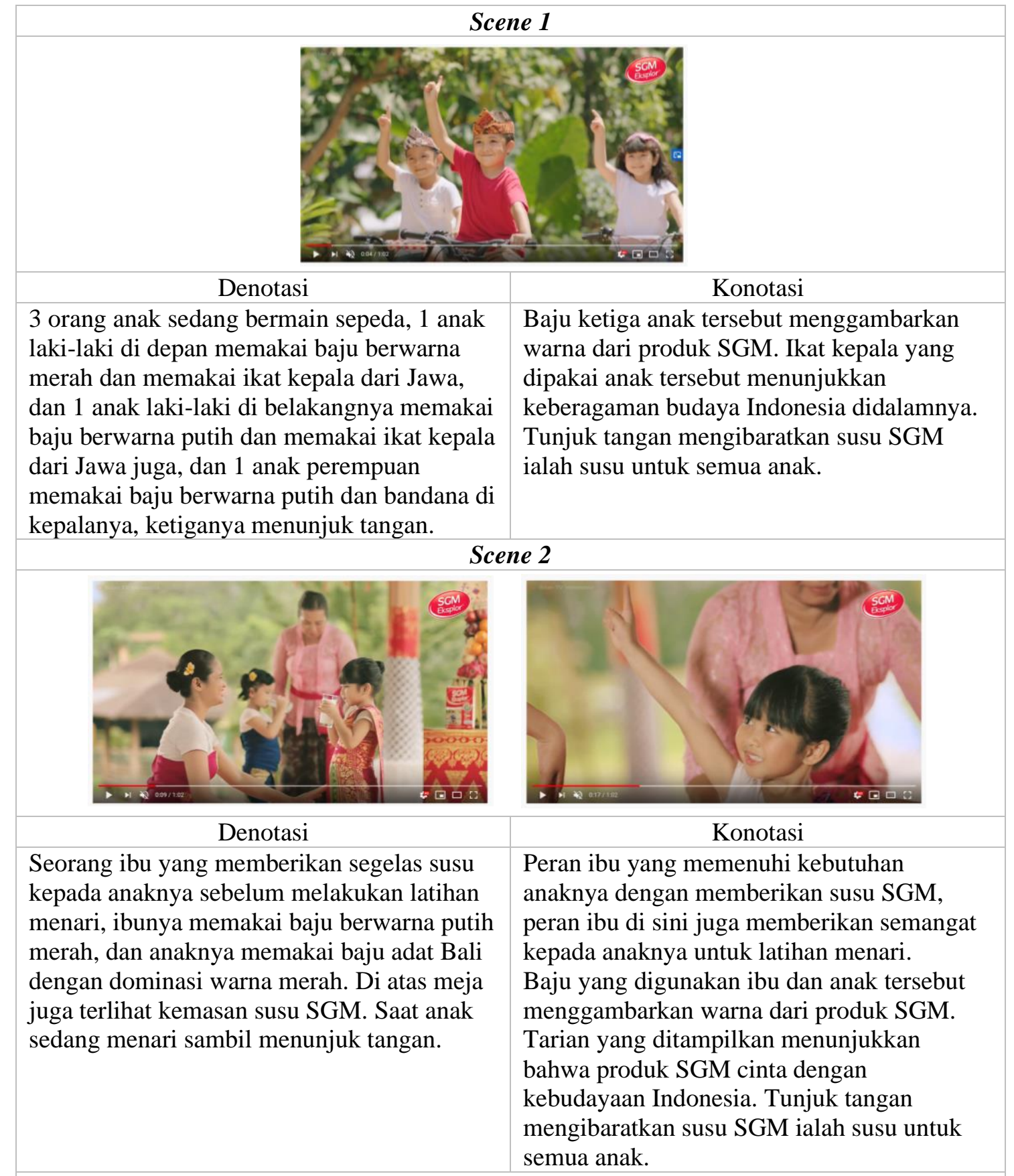

Scene 3

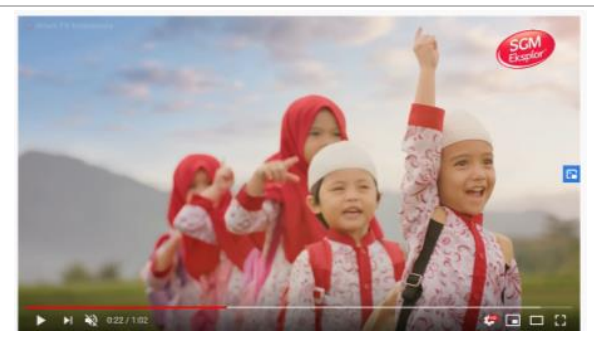

Denotasi

Anak-anak yang sedang berjalan melewati sawah untuk pergi mengaji di masjid sambil menunjuk tangan, menggunakan busana

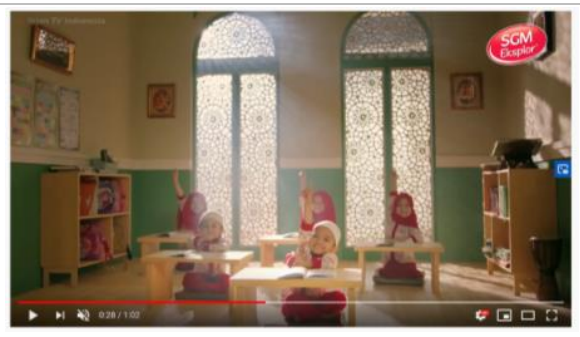

Konotasi

Busana yang digunakan menggambarkan warna dari produk SGM. Disini juga menggambarkan bahwa produk SGM tidak 
dengan dominasi berwarna merah dan putih. Sesampainya di masjid anak-anak duduk sambil menunjuk tangan lagi dan terdapat buku iqra'. ingin membeda-bedakan status sosial dan agama, jika di sambungkan dengan scene sebelumnya. Tunjuk tangan mengibaratkan susu SGM ialah susu untuk semua anak. Semangat yang terlihat pada anak-anak yang ingin pergi ke masjid untuk mengaji meski harus melewati sawah yang luas.

\section{Scene 4}

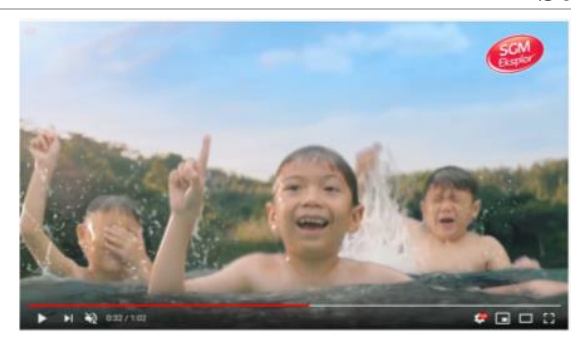

Denotasi

3 anak laki-laki yang sedang berenang dan ketiganya menunjuk tangan, disamping itu ada sepasang suami istri, suaminya memakai baju putih dengan garis merah dan istrinya memakai baju berwarna putih sambil menunjuk tangan juga.

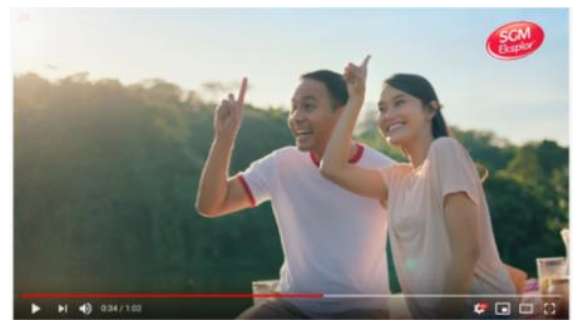

Konotasi

Baju yang digunakan pasangan suami istri ini menggambarkan warna dari produk SGM. Peran orangtua sangat mempengaruhi tumbuh berkembang anak dan dukungan orangtua memberikan semangat untuk anak. Tunjuk tangan mengibaratkan susu SGM ialah susu untuk semua anak. Semangat yang terlihat pada anak-anak yang sedang berenang.

\section{Scene 5}

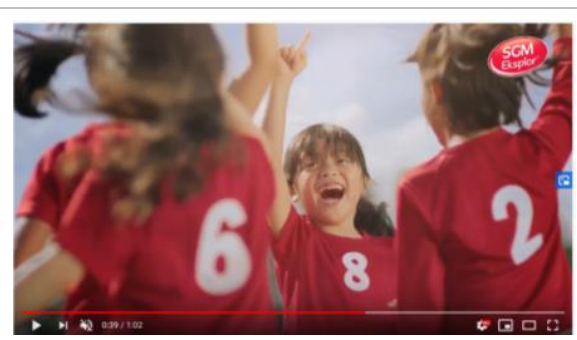

Denotasi

Anak-anak perempuan yang sedang bermain sepak bola dan salah satu anak menendang bola dan mencetak gol ke gawang lawan lalu menunjuk tangan. Anak-anak ini memakai baju berwarna merah yang bertuliskan angka berwarna putih. Di sana juga terlihat seorang ayah yang memakai baju putih dengan lengan berwarna merah sambil menunjuk tangan.

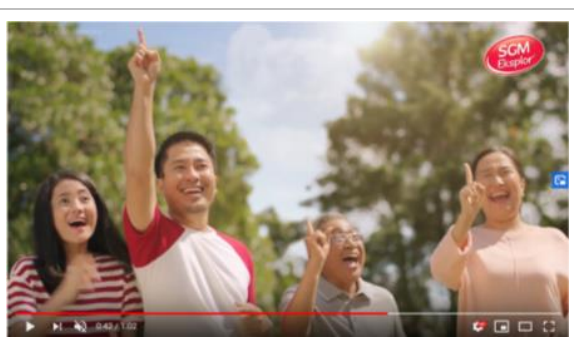

Konotasi

Biasanya sepak bola dimainkan oleh lakilaki, tetapi di sini dimainkan oleh perempuan, hal ini menunjukkan bahwa laki-laki dan perempuan memiliki kesetaraan. Pada scene ini juga ingin menunjukkan bahwa ayah memiliki peran yang sama dengan ibu, yaitu memberikan semangat dan dukungan kepada anaknya. Baju ayah dan anak tersebut menggambarkan warna pada produk SGM. Tunjuk tangan mengibaratkan susu SGM ialah susu untuk semua anak. 


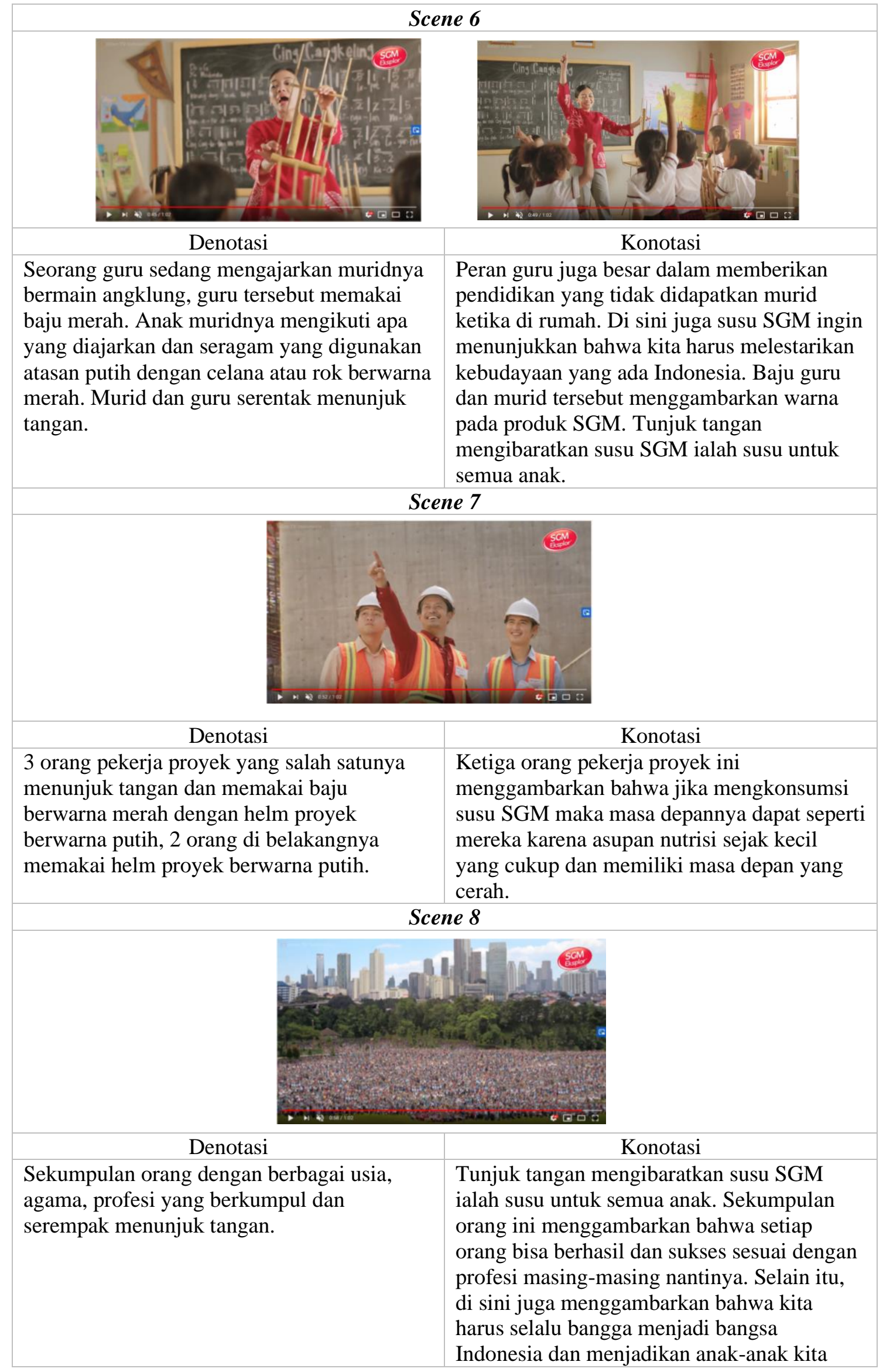


generasi maju. Generasi yang tidak

membeda-bedakan antar agama, suku, profesi

dan status sosial.

Pada hasil penelitian di atas, sudah dapat dijabarkan dan dimengerti bagaimana cara pandang iklan susu SGM tersebut menggunakan teori Barthes. Pada dasarnya, kita melihat iklan sesuai dengan denotasi karena dalam sekali melihat iklan tidak cukup untuk mendapatkan sudut pandang secara konotasi. Tetapi pada iklan susu SGM ini, dalam satu kali melihat iklannya, kita dapat langsung memahami denotasi dan konotasinya secara langsung. Iklan susu SGM ini menyisipkan budaya Indonesia dan segala macam kebiasaan masyarakat Indonesia dengan baik dan pesannya dapat tersampaikan.

\section{SIMPULAN}

Berdasarkan hasil penelitian tentang analisis semiotika (Roland Barthes) pada susu SGM versi "Tunjuk Tangan", dapat disimpulkan bahwa iklan memiliki tanda yang memiliki makna secara langsung maupun tidak langsung bagi penerimanya. Di dalam iklan ini ingin menunjukkan bahwa susu SGM memiliki gerakan untuk generasi maju dimana anak mampu menjadi apapun yang dia mau. Peran kedua orang tua juga sangat berpengaruh bagi perkembangan anak untuk tumbuh menjadi dewasa yang pintar, sehat, inspiratif dan sukses. Selain itu, iklan susu SGM ini mengingatkan kita untuk selalu bangga jadi Indonesia dengan menjaga dan melestarikan kebudayaan yang ada di Indonesia. Iklan ini juga menampilkan kehidupan sosial masyarakat kecil, menengah dan atas bertujuan agar kita tidak membeda-bedakan diantaranya. Dan semua berhak untuk hidup dan tumbuh menjadi orang yang berhasil. Susu SGM itu sendiri memproduksi susu dengan formula yang sesuai dengan kebutuhan ibu hamil dan menyusui hingga anak-anak sesuai dengan kebutuhannya tetapi dikemas dengan baik dan memberikan harga yang relatif terjangkau untuk seluruh masyarakat Indonesia agar tetap bisa mengkonsumsi susu formula dan dapat berkembang dengan baik karena adanya kecukupan gizi. Selain itu susu SGM dalam iklannya juga dapat tersampaikan pesannya bahwa susu SGM mengutamakan semua kalangan dan membuat generasi Indonesia lebih maju dengan mengkonsumsi susu SGM karena kebutuhan gizinya cukup.

\section{DAFTAR PUSTAKA}

Martono, M., Triyono, T., \& Septiani, R. A. (2018). Pembuatan video profil Sekolah Menengah Atas Negeri 7 Kota Tangerang Selatan berbasis audio visual sebagai media informasi dan promosi. Technomedia Journal, 3(1), 110-120.

Kasali, R. (2007). Manajemen periklanan, konsep dan aplikasinya di Indonesia. Jakarta: Pustaka Utama Grafiti.

Soekotjo, E. (2016). Bias gender dalam iklan susu (Analisis semiotika mengenai bias gender dalam iklan susu SGM versi" Tunjuk Tangan") (Doctoral dissertation, Widya Mandala Catholic University Surabaya).

Muhamad, F. (2017). Analisis semiotika: Pesan dakwah dalam arsitektur Masjid Agung Provinsi Banten. Al-Mabsut: Jurnal Studi Islam dan Sosial, 11(1), 46-69.

Yuwono, R. F. (2014). Efektivitas iklan Jayanata di Surat Kabar Jawa Pos terhadap Masyarakat Surabaya. Jurnal E-Komunikasi, 2(1).

Faladhin, J. (2018). Literasi media pada iklan Susu SGM versi "Jadikan Si

Kecil Generasi Maju”. Semantik, 7(1). 
Herawati, E., \& Rosidah, R. (2013). Tanda-tanda dalam iklan komersial di televisi (Analisis semiotika pada iklan Susu SGM Eksplor Presinutri 3). Humaniora, 4(1), 71-81.

Rosmiati, A. (2014). Pemakaian gaya bahasa pada iklan susu formula anak-anak. Gelar: Jurnal Seni Budaya, 12(1).

Youtube. (2018, April 26). Iklan SGM Eksplor - Tunjuk Tangan, Wujudkan si Kecil jadi

\#GenerasiMaju 60sec (2018). Diakses dari https://www.youtube.com/watch?v=KkFLFm9X90

Sarihusada. (2018). Diakses dari https://www.generasimaju.co.id 